\title{
Nonisothermal Cold Crystallization Kinetics of Poly(aryl ether diphenyl ether ketone)
}

\author{
Zhao Bin QIU, Hong Wei ZHou, ${ }^{*}$ Zhi Shen Mo, ${ }^{\dagger}$ \\ Hong Fang ZHANG, and Zhong Wen WU* \\ Polymer Physics Laboratory, Changchun Institute of Applied Chemistry, \\ Academia Sinica, Changchun 130022, People's Republic of China \\ * Department of Chemistry, Jilin University, Changchun 130023, People's Republic of China
}

(Received July 19, 1999)

KEY WORDS Poly (ether diphenyl ether ketone) / Crystallization / Differential Scanning Calorimetry /

Poly(ether ether ketone) (PEEK) is well known as a high-performance engineering thermoplastics possessing excellent mechanical properties, good solvent resistance and high thermal stability. ${ }^{1,2}$ However, its relatively low glass transition temperature $\left(T_{\mathrm{g}}, 143^{\circ} \mathrm{C}\right)$ and comparatively high price limit its widespread application. By varying the ratio of ketone / ether groups, one can improve the low $T_{\mathrm{g}}$ of this kind of polymer. ${ }^{1-6}$ As an alternative method to improve its heat resistance, replacement of its phenylene moiety to biphenylene moiety has been proved to be effective. ${ }^{7}$ Among them, poly(aryl ether diphenyl ether ketone) (PEDEK) possesses a higher thermal resistance by replacement of its phenylene moiety to biphenylene moiety ; moreover, its mechanical, physical, and other properties which are compatible with those of PEEK are still maintained. PEDEK has the following chemical repeating unit :

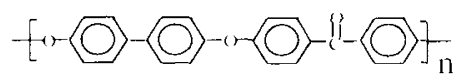

Up to now, only a few studies have reported on this polymer, mainly on its synthesis, ${ }^{4}$ crystal structure, ${ }^{8}$ double melting behavior, ${ }^{9}$ and variation in unit cell parameters with crystallization temperature ${ }^{10}$ As the practical processes such as extrusion, moulding and film production were usually performed under dynamic, nonisothermal conditions, it is of great significance to study the nonisothermal crystallization process quantitatively. The present article reports the nonisothermal cold crystallization behavior of PEDEK.

\section{EXPERIMENTAL}

PEDEK was prepared by polycondensation of $4,4^{\prime}$ diphenol with $4,4^{\prime}$-difluorobenzophenone, diphenylsulfone as solvent and alkali metal carbonate as catalyst through a nucleophilic substitution route. The glass transition temperature $\left(T_{\mathrm{g}}\right)$ of $1711^{\circ} \mathrm{C}$ and melting temperature $\left(T_{\mathrm{m}}\right)$ of $409^{\circ} \mathrm{C}$ were measured by differential scanning calorimetry (DSC). The inherent viscosity of the polymer used was $1.30 \mathrm{dL} \mathrm{g}^{-1}$ (measured at $25^{\circ} \mathrm{C}$ on a $0.1 \%$ solution of the polymer in $98 \%$ sulphuric acid). The brown amorphous glassy film was obtained by quenching the hot-pressed sheets into ice/water mixture

\footnotetext{
${ }^{\dagger}$ To whom correspondence should be addressed.
}

as quickly as possible from the melt $\left(440^{\circ} \mathrm{C}\right)$. The film was confirmed to be amorphous by wide-angle X-ray diffraction pattern (WAXD).

A Perkin-Elmer DSC-7 apparatus was used for measuring nonisothermal cold crystallization kinetics. The amorphous samples were heated at constant heating rates in the range from 2.5 to $30^{\circ} \mathrm{C} \mathrm{min}{ }^{-1}$. All operations were performed under a nitrogen purge. Sample weight varied between $8-10 \mathrm{mg}$. The exothermic crystallization peak was then recorded as a function of temperature. The relative degree of crystallinity, $X_{t}$, and absolute degree of crystallinity, $X_{c}$, as a function of temperature $T$ are defined as

$$
\begin{gathered}
X_{\mathrm{i}}=\frac{\int_{T_{0}}^{T}\left(\frac{\mathrm{d} H_{\mathrm{c}}}{\mathrm{d} T}\right) \mathrm{d} T}{\int_{T_{\mathrm{i}}}^{T_{\infty}}\left(\frac{\mathrm{d} H_{\mathrm{c}}}{\mathrm{d} T}\right) \mathrm{d} T} \\
X_{\mathrm{c}}=\frac{\int_{T_{\mathrm{it}}}^{T} \frac{\mathrm{d} H_{\mathrm{c}}}{\mathrm{d} T} \mathrm{~d} T}{\Delta H_{\mathrm{m}}^{0}}
\end{gathered}
$$

Where $T_{\mathrm{o}}$ and $T_{\infty}$ ( represent the onset and end of crystallization temperatures, respectively. $H_{c}$ is the enthalpy for unit mass of sample with unit $\mathrm{J} \mathrm{g}^{-1} . \Delta H_{\mathrm{m}}{ }^{0}$ is the heat of fusion of a perfect PEDEK crystal. The absolute crystallinity was calculated on the basis of the heat of fusion using a value of $\Delta H_{\mathrm{m}}{ }^{0}=169 \mathrm{~J} \mathrm{~g} \mathrm{~g}^{-1} \cdot{ }^{11}$

\section{RESULTS AND DISCUSSION}

Figure 1 showed typical DSC scans of PEDEK on heating from the amorphous at various rates. This figure revealed that the exothermic peak $T_{\mathrm{p}}$ on heating shifted to higher temperature and became broader when the heating rate increased. At $2.5^{\circ} \mathrm{C} \mathrm{min}{ }^{-1}$, the peak temperature $T_{\mathrm{p}}$ was observed at about $189.8^{\circ} \mathrm{C}$, increasing to $202.8^{\circ} \mathrm{C}$ at the highest heating rate of $30^{\circ} \mathrm{C} \mathrm{min}{ }^{-1}$. The values of $T_{\mathrm{p}}$, their corresponding peak times $t_{\max }$, the crystallization enthalpies $\Delta H_{\mathrm{c}}$, the relative crystallinity $X_{\mathrm{t}}$ and the absolute crystallinity $X_{\mathrm{c}}$ of the nonisothermal cold crystallization for PEDEK under different heating rates were collected in Table I.

Integration of the exothermic peaks during the nonisothermal scan gave the relative degree of crystallinity as a function of temperature. The results were shown in 


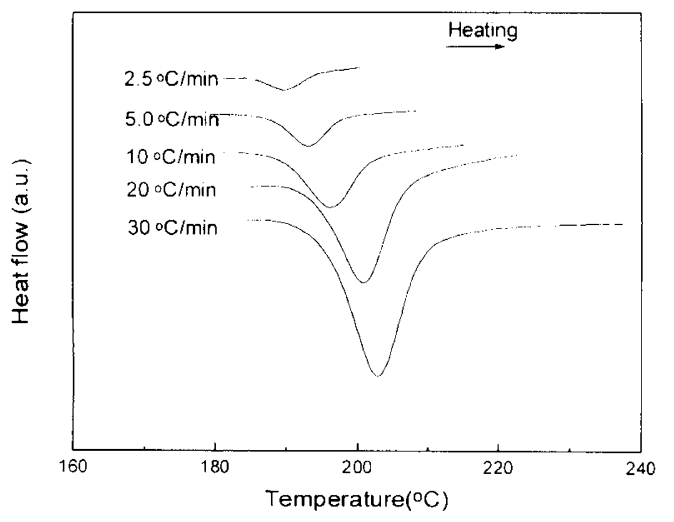

Figure 1. Heat flow vs. temperature during nonisothermal cold crystallization at different rates.

Table 1. Peak temperature $\left(T_{\mathrm{p}}\right)$, peak time $\left(t_{\max }\right)$, crystallization enthalpy $\left(\Delta H_{\mathrm{c}}\right)$, relative crystallinity $\left(X_{\mathrm{t}}\right)$ at the maximum rate of heat flow, and absolute degree of crystallization $\left(X_{\mathrm{c}}\right)$, during nonisothermal cold crystallization of PEDEK

\begin{tabular}{cccccc}
\hline$\Phi /{ }^{\circ} \mathrm{C} \mathrm{min}^{-1}$ & $T_{\mathrm{p}} /{ }^{\circ} \mathrm{C}$ & $t_{\max } / \min$ & $\Delta H_{\mathrm{c}} / \mathrm{J} \mathrm{g}^{-1}$ & $X_{\mathrm{t}} / \%$ & $X_{\mathrm{c}} / \%$ \\
\hline 2.5 & 189.8 & 3.50 & 15.1 & 44.5 & 8.9 \\
5.0 & 193.2 & 2.79 & 16.0 & 47.0 & 9.5 \\
10 & 196.1 & 1.51 & 18.0 & 47.5 & 10.7 \\
20 & 200.9 & 0.82 & 16.2 & 49.5 & 9.6 \\
30 & 202.8 & 0.61 & 17.1 & 48.0 & 10.1 \\
\hline
\end{tabular}

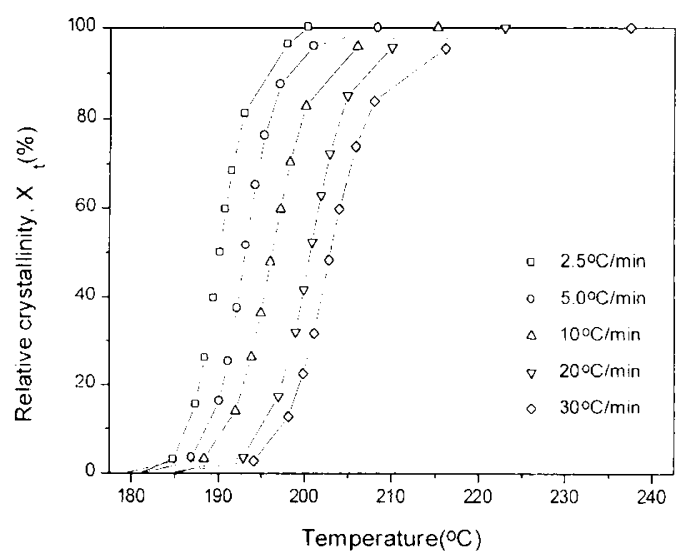

Figure 2. Development of relative crystallinity with temperature for nonisothermal cold crystallization.

Figure 2. The well-known Avrami equation is used to analyze the isothermal crystallization kinetics, which assumed that the relative degree of crystallinity developed with crystallization time $t,{ }^{12}$

$$
1-X_{\mathrm{t}}=\exp \left(-Z_{\mathrm{t}} t^{n}\right)
$$

where $n$ is the Avrami crystallization exponent depending on the nature of nucleation and growth geometry of the crystals; $Z_{\mathrm{t}}$ is a composite rate constant involving both nucleation and growth rate parameters. Whereas eq 3 is reasonable to certain extent for many systems, some modified forms are proposed in order to fit experimental results obtained from nonisothermal crystallization process. Considering the nonisothermal character of the process investigated, Jeziorny pointed out that the value of rate parameter $Z_{\mathrm{t}}$ should be adequately corrected. ${ }^{13}$ The factor which should be considered was the

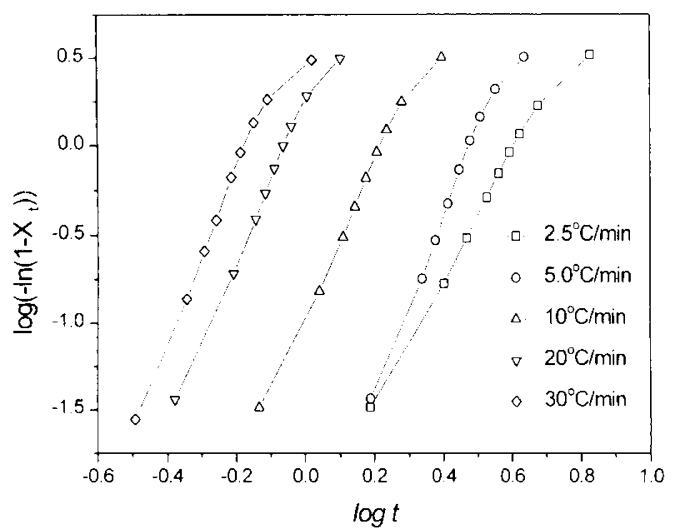

Figure 3. Plots of $\log \left[-\ln \left(1-X_{\mathrm{t}}\right)\right]$ vs. $\log t$ for nonisothermal cold crystallization.

Table II. Effect of heating rates on crystallization kinetics of PEDEK

\begin{tabular}{|c|c|c|c|}
\hline$\Phi /{ }^{\circ} \mathrm{C} \min { }^{1}$ & $n$ & $Z_{\mathrm{t}}$ & $t_{1 / 2} / \min ^{\mathrm{a}}$ \\
\hline 2.5 & 3.8 & $4.97 \times 10^{-3}$ & 3.67 \\
\hline 5.0 & 5.3 & $2.77 \times 10^{-3}$ & 2.80 \\
\hline 10 & 4.7 & $9.56 \times 10^{2}$ & 1.50 \\
\hline 20 & 4.9 & 1.96 & 0.81 \\
\hline 30 & 5.1 & 7.96 & 0.62 \\
\hline
\end{tabular}

${ }^{a}$ Here, the parameter $t_{1 / 2}$ is given by $t_{1 / 2}=\left(\ln 2 / Z_{\mathrm{t}}\right)^{1 / n}$.

cooling rate $\Phi$. Assuming constant or approximately constant $\Phi$, the final form of the parameter characterizing the kinetics of nonisothermal crystallization was given by $\log Z_{\mathrm{c}}=\log Z_{\mathrm{t}} / \Phi$. Plots of $\log \left[-\ln \left(1-X_{\mathrm{t}}\right)\right] v s . \log t$ were shown in Figure 3. Each curve had a linear portion followed by a gentle roll-off at longer times. Usually, this deviation is considered to be due to the secondary crystallization which is caused by the spherulite impingement in the later stage. The nonisothermal crystallization kinetic parameters were listed in Table II. For nonisothermal cold crystallization, the average value of Avrami exponent were $n \approx 5$. It suggested that the nonisothermal cold crystallization might correspond to a three-dimensional solid sheaf growth with athermal nucleation. ${ }^{14}$

As the nonisothermal crystallization is a ratedependent crystallization process, it can be analyzed using the Ozawa analysis. ${ }^{15}$ Ozawa accounted for the effect of cooling (or heating) rate $\Phi$ on crystallization from the melt (or the glassy state), and modified the Avrami equation by replacing $t$ in eq 3 with $T / \Phi$. The Ozawa equation is :

$$
1-X_{\mathrm{t}}=\exp \left[\frac{K(T)}{\Phi^{m}}\right]
$$

where $K(T)$ was heating or cooling function, $m$ was Ozawa exponent which depended on the crystal growth and nucleation mechanism. The Ozawa equation was also used in this study to deal with the data of nonisothermal crystallization. Results of the Ozawa analysis are shown in Figure 4, plotted as $\log \left[-\ln \left(1-X_{\mathrm{t}}\right)\right]$ versus $\log \Phi$, for temperatures from 190 to $205^{\circ} \mathrm{C}$ for the nonisothermal cold crystallization. If the Ozawa treatment could describe the nonisothermal crystallization process of PEDEK correctly, the plot of $\log \left[-\ln \left(1-X_{\mathrm{t}}\right)\right]$ versus $\log \Phi$ would result in a series of parallel lines of slope 


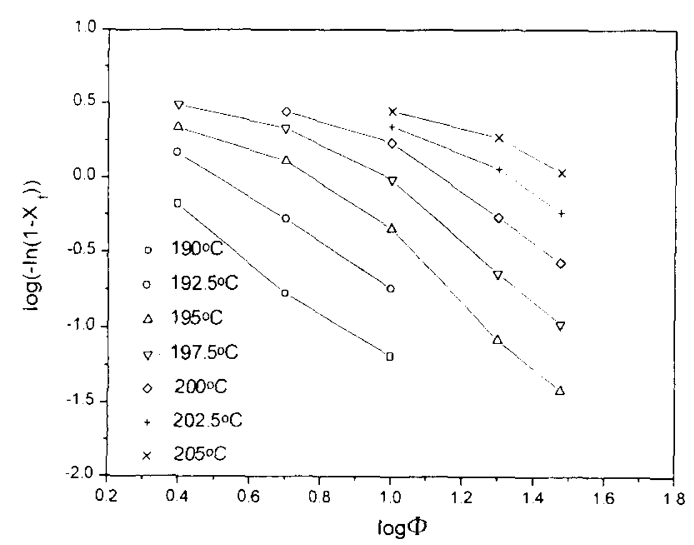

Figure 4. Ozawa plots of nonisothermal cold crystallization of PEDEK.

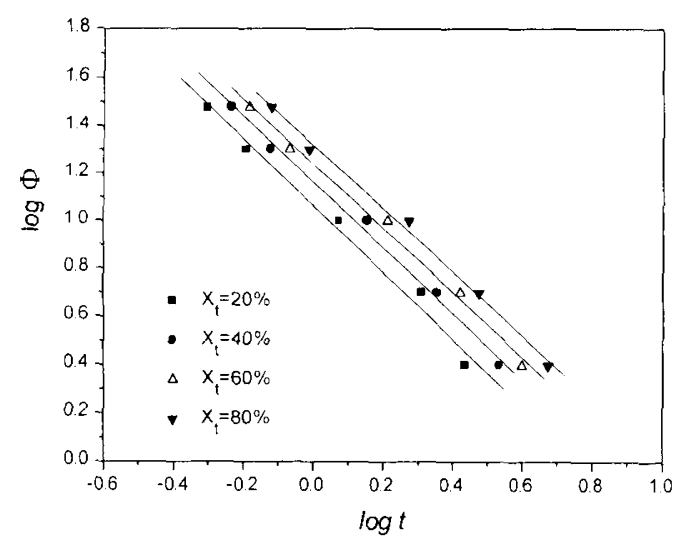

Figure 5. Plots of $\log \Phi_{v s} . \log t$ for nonisothermal cold crystallization of PEDEK.

$-m$ and intercept $\log K(T)$. But in fact, Figure 4 shows some obvious zigzag lines, which is similar to that observed in PEEK ${ }^{16}$ and PEEKK. ${ }^{17}$ The changing slopes indicate that $m$ is not constant with temperature during the primary crystallization process. The general curvatures seen in Figure 4 make it impossible to determine the cooling or heating function $K(T)$ by the Ozawa method. The reason why the nonisothermal crystallization of PEDEK does not follow the Ozawa equation may be due to secondary crystallization and in fact the inaccurate assumption of a constant heating function over the entire crystallization process.

Recently a convenient kinetic method proposed by our research group was adopted to deal with nonisothermal data of many polymer systems. ${ }^{17-20}$ The convenient method modified by combining the Avrami equation with the Ozawa equation is :

$$
\log \Phi=\log F(T)-a \log t
$$

where the parameter $F(T)=\left[K(T) / Z_{\mathrm{t}}\right]^{1 / m}$ refers to the value of cooling or heating rate, which has to be chosen at unit crystallization time when the measured system amounts to a certain degree of crystallinity ; $a$ is the ratio of Avrami exponent $n$ to the Ozawa exponent $m$ (i.e., $a=n / m$ ). At a given degree of crystallinity, the plots of $\log \Phi v s . \log t$ were given in Figure 5, from which the values of $a$ and $F(T)$ could be obtained by the slopes and the intercepts of these lines, respectively (Table III). The values of $F(T)$ increases systematically with raising the
Table III. Nonisothermal crystallization kinetic parameters of PEDEK at different degrees of crystallinities by the combination of Avrami and Ozawa equations.

\begin{tabular}{ccc}
\hline$X_{\mathrm{t}} / \%$ & $F(T)$ & $a$ \\
\hline 20 & 0.76 & 0.72 \\
40 & 0.85 & 0.73 \\
60 & 0.92 & 0.74 \\
80 & 0.99 & 0.75 \\
\hline
\end{tabular}

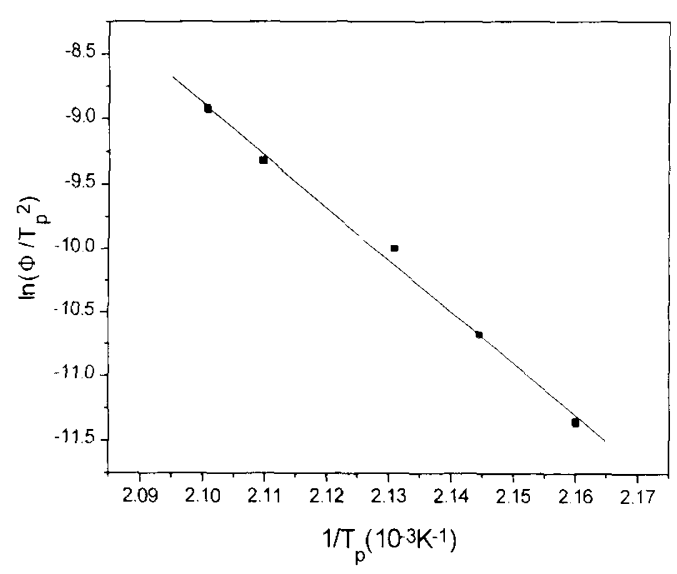

Figure 6. Kissinger plots for estimating the activation energy of nonisothermal crystallization of PEDEK.

relative crystallinity, indicating that at unit crystallization time, a higher heating rate should be used in order to obtain higher degree of crystallinity; but the values of $a$ are almost constant, which are about 0.73 for nonisothermal cold crystallization.

The activation energy of crystallization is derived by Kissinger equation as the following form : ${ }^{21}$

$$
\left[\mathrm{d}\left(\ln \Phi / T_{\mathrm{p}}^{2}\right)\right] /\left[\mathrm{d}\left(1 / T_{\mathrm{p}}\right)\right]=-\Delta E / R
$$

where $R$ is the universal gas constant. Accordingly, in the light of the results in Table I, the slopes of $\ln \Phi / T_{\mathrm{p}}^{2} \mathrm{vs}$. $1 / T_{\mathrm{p}}$ will give $\Delta E / R$ (Figure 6). The slope of $\ln \Phi / T_{\mathrm{p}}^{2} v s$. $1 / T_{\mathrm{p}}$ plot will give the crystallization activation energy, i.e., $\Delta E=-R \times$ slope. The activation energies of nonisothermal cold crystallization can be determined as 335.7 $\mathrm{kJ} \mathrm{mol}^{-1}$. The value of $\triangle E$ of PEDEK is higher than that of PEEK $\left(218 \mathrm{~kJ} \mathrm{~mol}^{-1}\right),{ }^{16}$ indicating that in PEEKs family the stiffer members are more difficult to crystallize than the flexible ones.

Acknowledgment. This research is supported by the National Natural Science Foundation of China and the Chinese "863" high technology funds. The authors also express their warm thanks for the reviewer's good advice and critical comments.

\section{REFERENCES}

1. Eur. Pat. Appl. 1879(1979), Imperial Chem. Ind. Ltd., invs. : J. B. Rose and P. A. Staniland, Chem. Abstr., 92, $42599 \mathrm{~g}$ (1980).

2. Brit. Pat. 1558671(1980), Imperial Chem. Ind. Ltd., invs. : J. B. Rose, Chem. Abstr., 92, $181877 \mathrm{j}(1980)$.

3. T. E. Attwood, P. C. Dawson, J. L. Freeman, L. R. J. Hoy, J. B. 
Rose, and P. A. Staniland, Polym. Prepr., Am. Chem. Soc., Div. Polym. Chem., 20, 191(1979).

4. T. E. Attwood, P. C. Dawson, J. L. Freeman, L. R. J. Hoy, J. B. Rose, and P. A. Staniland, Polymer, 22, 1096(1981).

5. A. J. Lovinger and D. D. Davis, Polym. Commun., 25, 175 (1984).

6. Z. W. Wu, Kobunshi Ronbunshu, 38, 603(1981).

7. W. J. Zhang, X. L. Ji, J. Yuan, H. Na, J. Z. Wang, and Z. W. Wu, Chemical Journal of Chinese University, 14, 1308(1993).

8. D. J. Blundell and V. Bayon, Polymer, 34, 1354(1993).

9. X. L. Ji, W. J. Zhang, and Z. W. Wu, J. Polym. Sci. B, 35, 431 (1996).

10. X. L. Ji, X. F. Qiu, W. J. Zhang, Z. S. Mo, H. F. Zhang, and Z. W. Wu, Polym. J., 7, 601(1998).

11. X. L. Ji, Ph. D. Thesis, Jilin University, Changchun(1995).
12. M. Avrami, J. Chem. Phys., 8, 212 (1940).

13. A. Jeziorny, Polymer, 19, 1142 (1978).

14. B. Wunderlich, "Macromolecular Physics", Vol.2, Academic Press, New York, N.Y., 1977.

15. T. Ozawa, Polymer, 12, 150 (1971).

16. P. Cebe and S.-D.Hong, Polymer, 27, 1183 (1986).

17. T. X. Liu, Z. S. Mo, S. E. Wang, and H. F. Zhang, Polym. Eng. Sci., 37, 568(1997).

18. T. X. Liu, Z. S. Mo, and H. F. Zhang, J. Appl. Polym. Sci., 67, 815(1998).

19. Y. X. An, L. S. Dong, Z. S. Mo, T. X. Liu, and Z. L. Feng, J. Polym. Sci., B, 36, 1305(1998).

20. S. Y. Liu, Y. N. Yu, Y. Cui, H. F. Zhang, and Z. S. Mo, J. Appl. Polym. Sci., 70, 2371(1998).

21. H. E. Kissinger, J. Res. Natl. Stds., 57, 217 (1956). 